\title{
Displaced Sudanese Voices on Education, Dignity, AND Humanitarian Aid
}

\author{
Friedrich W. Affolter and Carine Allaf ${ }^{1}$
}

\begin{abstract}
Education is viewed by Sudanese refugees and internally displaced persons as a key prerequisite for social status, prestige, socio-economic survival, and therefore human dignity. Using Sudan as a case study, the article demonstrates that humanitarian aid - which claims to ensure the basic conditions for a life with dignity-often attributes less importance to education than to other sectors such as water, nutrition, and health. Utilizing anecdotal evidence from internally displaced persons in conflict-affected regions of Sudan, this article illustrates that the humanitarian aid agenda fails to adequately address what their target population most demands: education.
\end{abstract}

\section{Résumé}

L'éducation est considérée par les réfugiés soudanais et les personnes déplacées à l'intérieur du Soudan comme une condition préalable essentielle pour le statut social, le prestige, la survie socioéconomique et donc la dignité humaine. Utilisant le Soudan comme étude de cas, l'article montre que l'aide humanitaire, qui prétend assurer les conditions de base pour une vie dans la dignité, attribue souvent moins d'importance à l'éducation qu'à d'autres secteurs tels que l'eau, la nutrition ou la santé. À l'aide de témoignages anecdotiques de personnes déplacées dans les régions touchées par le conflit au Soudan, cet article montre que le programme humanitaire ne répond pas adéquatement au besoin principal de sa population cible : l'éducation.

\section{Introduction}

The Sphere Project's Humanitarian Charter and Minimum Standards in Humanitarian Response defines humanitarianism as "our shared conviction as humanitarian agencies that all people affected by disaster or conflict have a right to receive protection and assistance to ensure the basic conditions for life with dignity." Later the handbook argues that the "right to life with dignity ... entails the duty to preserve life where it is threatened. Implicit in this is the duty not to withhold or frustrate the provision of life-saving assistance." 3 It then continues to argue, "Dignity entails more than physical well-being; it demands respect for the whole person, including the values and beliefs of individuals and affected communities, and respect for their human rights, including liberty, freedom of conscience and religious observance."

Numerous organizations' mission statements, international covenants, mandates, and resolutions call for a commitment to dignity. ${ }^{5}$ This article aims to illustrate how the provision of basic education services in humanitarian situations continues to be underfunded and undervalued, despite the fact that populations affected by conflict or disasters consider access to education an integral component of a life with dignity. Using Sudan as an example, this article $r$ illustrates that education is indeed a valued and sought-after asset, $^{6}$ and that humanitarian interventions that give preference to the provision of food, water, and health services only, fail to take into account the values and beliefs of their target beneficiaries.

In this article, we begin with a situation analysis of Sudan, a country suffering from "chronic emergencies" for more than a decade. We then present an education context analysis, which illustrates the dim prospects of Sudanese IDP and refugee children and youth to obtain access to adequate and 
quality education. The article will demonstrate, on the basis of a comparison of financial allocation amounts made by different humanitarian funds, that education is not being given equal priority, despite the fact that target populations consider it of equal importance. Then using voices of those affected, we present why education makes a fundamental difference in the lives of children and youth affected by crisis. We conclude by providing evidence for why education must not only be included but prioritized when funding and delivering humanitarian responses, and highlight the importance of critically looking at an education system and its impact on a nation's development and citizen building.

\section{Sudan Situation Analysis}

Prior to the referendum in July 2011 declaring South Sudan an independent country, Sudan was the largest country in Africa. After the referendum, Northern Sudan comprises 17 states, including the three protocol areas of Abyei, Blue Nile State, and Southern Kordofan State. ${ }^{7}$ The vastness of Sudan's geographical landscape, the high number of nomadic people (roughly 8.5 per cent of the population), civil conflict, insecurity, and high incidence of drought and desertification make accurate demographic data almost impossible, and, as such, there are no accurate understandings of the needs of its people. This diverse and complicated landscape further illustrates how one country such as Sudan houses both conflict and peaceful zones side-by-side, further complicating notions of aid and development.

Sudan has been in a state of ongoing conflict since even before its independence from the British-Egypt condominium rule in 1956. Generally the civil war is described as a conflict between Muslims and Christians or Arabs and Africans, but van der Zwan writes, "The reality is that the conflict has been fuelled by the chronic underdevelopment of marginalized areas of Sudan, coupled with often violent competition for access to political and economic power. Local conflicts, over grazing rights, access to water and control over humanitarian aid, as well as ethnic and religious manipulation and mobilization, have also been fuelling instability and tensions." ${ }^{8}$ Even after the Comprehensive Peace Agreement of 2005 and the referendum of July 2011, tensions have erupted between Sudan and South Sudan, and the Government of Sudan (GoS) has continued to use military means in the three protocol areas, leading to additional displacements and alleged war atrocities and human rights violations. ${ }^{9}$ There are also ongoing conflicts between the Dinka Ngok and the Misseriya groups in the disputed region of Abyei, as well as resistance groups and the Government in Darfur.

As a result of GoS involvement in the ongoing conflicts, the government reduced its budget by 36.5 per cent, decreasing their spending on the social sectors and lower fiscal transfers to the states for basic service delivery. ${ }^{10}$ At the same time, high inflation rates drove food prices upwards, increasing vulnerability among rural people and the urban poor. ${ }^{11}$

Sudan suffers from a habitual state of endemic poverty. This is a major area of concern, because high poverty rates in disadvantaged states are correlated with conflict. Approximately 46.5 per cent of the population lives under the national poverty line of less than one dollar a day. Although political conflict is the most obvious reason for insecurity in Sudan, inter-family fighting and criminality are also key factors. In addition to poverty and insecurity, Sudan has experienced extreme demographic shifts due to urbanization for economic reasons and displacement as a result of conflict. Compounding these difficulties, over 40 per cent of the population is under the age of $15 .^{12}$ In a country where poverty and insecurity are major concerns, in addition to a quickly growing and changing population, the government's lack of capacity has increased vulnerability and decreased trust and support, making governance in Sudan a major limitation. All these factors have directly and indirectly contributed to vulnerability, conflict, and poverty. ${ }^{13}$

Sudan is an interesting country in which to investigate the funding of education in a humanitarian response, because it can be classified as both a conflict-affected country (where education can potentially be a part of the humanitarian response but not always a priority) and as stable or postconflict context (where education is definitely included in development efforts). Thus various parts of the country fall onto various areas of the relief-to-development continuum. Sudan continues to have outbreaks of violence, especially in the three protocol areas, in addition to the Darfurs where conflicts are ongoing and are further complicated by flash flooding and other natural disasters. ${ }^{14}$

The World Bank Education Sector Report (2012) estimates that there are 4.3 million internally displaced persons (IDPs) either living inside IDP camps or in other "spontaneous settlements," while the Internal Displacement Monitoring Centre reports IDP numbers to be closer to 5 million. Prior to the separation of the two countries, Sudan had the highest number of IDPs in Africa. ${ }^{15}$ Many of the displaced have spent almost a decade in emergency camps, although the average length of displacement for the internally displaced is roughly 20 years. ${ }^{16}$ Ferris and Winthrop argue that "IDPs-although numbering far more than refugees-have a descriptive rather than a legal definition, having no binding international convention, and have no dedicated UN agency in charge of their protection and assistance." 17 The government is in charge of IDPs, and 
this is problematic in a context like Sudan, where the government played a role in the conflict, resulting in displacement. Interestingly, of the 10 countries with the largest IDP population (one being Sudan), Colombia, Iraq, and Turkey are the only ones that have taken steps to include IDP children and youth in their laws and policies. However, more importantly, even when there are laws and policies, "there is almost always a gap between the legal framework and the implementation on the ground." 18 Complex emergencies and natural disasters continue to result in new waves of IDP movements mainly in the Darfur states and the three protocol areas. The closing of the border points between Sudan and South Sudan will impede traditional nomadic migration routes and result in new spontaneous settlements near the South Darfur border. Over half a million school-age children are affected by this situation and, as a result, many may not have access to schooling in the new settlements.

\section{Education Context Analysis}

Across Sudan, gross enrolment in basic education remains at 72 per cent, behind schedule to meet the Millennium Development Goals of universal primary education by $2015 .{ }^{19}$ In certain population groups, such as nomadic populations, gross enrolment is below 75 per cent, ${ }^{20}$ and other vulnerable children such as IDPs, returnees, refugees, orphans, children with special needs, and children from rural underserved communities are least likely to access education services. Additionally, according to the same statistics, one million children have never attended school, and 62 per cent of children who are not in school are girls. A poor rural girl's chances to access a quality education is 25 percentage points lower than that of a well-off urban boy. ${ }^{21}$ As expected, areas of Sudan that are more peaceful have higher enrolment rates of education, and the conflictaffected regions have experienced higher enrolment areas with periods of peace. Yet as a result of recent and ongoing military conflicts in the three protocol areas, displacement continues to take place, leading to further decreased enrolment rates. Consequently, pressure is building on education resources in neighbouring "stable" states such as White Nile, Sennar, and North Kordofan, to support the recently displaced, straining their education system.

Under-investment in the education of children and youth irreversibly jeopardizes the hopes for a better future of millions of Sudanese children. They are bound to grow up unskilled, unhealthy, and with little chance for future employment. ${ }^{22}$ According to the 2012 World BankEducation Sector report, Sudan "spends less as a share of total public spending and of GDP than do countries with similar incomes and other countries in the region with comparable dependency ratios" on education. ${ }^{23}$ Sudan spends just 2.7 per cent of its GDP on education, compared with the 3-7 per cent that other lower-middle-income countries spend (such as Egypt, Morocco, and Cote d'Ivoire). Furthermore, GoS actions further complicate receiving external support. For example, because Sudan did not ratify the 2005 Cotonou Agreement, the country is ineligible to receive any money from the European Development Fund. ${ }^{24}$ In addition, the separation of South Sudan from Sudan resulted in donors deciding to at least halve their aid portfolio for Sudan in 2011. Furthermore, Sudan's decision not to grant access to humanitarian service providers to war-affected regions prompted donors to temporarily freeze or reroute humanitarian aid earmarked for Sudan. Finally, the financial crisis hitting Europe and North America further strained donors' budgetary possibilities to support humanitarian aid efforts in Sudan.

\section{Education as a Humanitarian Pillar}

Aid allocations to education in humanitarian contexts have doubled since 2006, in part as a result of key developments that include the Inter-Agency Network for Education in Emergencies (INEE), established at the 2000 World Education Forum to improve interagency communication and collaboration for education in emergencies; the expansion of the Central Emergency Response Funds (CERF); country-level pooled funds such as the Common Humanitarian Funds (CHF) and the Emergency Response Fund (ERF) have begun to include education; and in 2006 the Inter-Agency Standing Committee (IASC) supported the formation of the Education Cluster and recognized the sector in the humanitarian response. ${ }^{25}$ Still in humanitarian emergencies, only 2.3 per cent of all humanitarian funding goes to education. According to the Education Cluster Unit (2011), education has been one of the most underfunded sectors in the last decade. ${ }^{26}$

Progress to acknowledge the importance of education in humanitarian contexts continues. In October 2008, the Sphere Project announced a companionship with the INEE recognizing the quality and recommending the use of the INEE Minimum Standards for Education: Preparedness, Response, Recovery, as a companion to the Sphere handbook. ${ }^{27}$ The UN General Assembly adopted resolution A/64/L.58, "The Right to Education in Emergency Settings," on 9 July 2010, which emphasized education in all stages of humanitarian response, safe and protective educational environments, reconstruction and post-emergency situations, and the importance of political will and financing of education efforts. ${ }^{28}$ In February 2011, the U.S. Agency for International Development (USAID) released their 2011-2015 Education Strategy, with the third goal being "Increased equitable access to education in crisis and 
conflict environments for 15 million learners by 2015," and in September 2012, UN Secretary General Ban Ki-Moon launched the Education First Initiative, reinforcing the 2010 resolution of protecting the right of children and youth to a quality education in humanitarian emergencies and conflicts.

Nevertheless, education in humanitarian contexts remains under-financed. As indicated in table 1, which compares global humanitarian funding to the education sector from 2010 to 2012 , allocations to education in humanitarian contexts is small and on continued decline. Across the board, it is one of the lowest funded sectors, and the percentage of education funding of the grand total of humanitarian contributions is decreasing.

Table 1. Humanitarian funding allocated to education

\begin{tabular}{lll}
\hline Year & Total funding $(\$)$ & $\%$ of total \\
\hline 2010 & $365,682,183$ & 2.3 \\
2011 & $174,524,644$ & 1.3 \\
2012 & $66,372,836$ & 0.7 \\
\hline
\end{tabular}

Source: Financial Tracking Service, generated on 24 September 2012

Table 2 presents the percentage of education funding of overall ERF, CHF, and CERF funding from 2010 to 2012. Although it has remained relatively stable, it is still quite low in total contribution to education, further illustrating that education is not necessarily prioritized in a humanitarian context.

Table 2. Percentage of overall funding dedicated to education

\begin{tabular}{ll}
\hline Year & \% of total \\
\hline 2010 & 3.01 \\
2011 & 2.97 \\
2012 & 3.04 \\
\hline
\end{tabular}

Source: UN OCHA 2012 and personal communication with OCHA Geneva

Table 3 presents an overview of funding allocations that humanitarian sectors in Sudan absorb from ERF, CHF, and CERF 2011 funding. If actions speak louder than words, it is fair to conclude that education is not given the priority of most other humanitarian aid sectors.
Table 3. Funding allocations for humanitarian sectors, Sudan, 2012

\begin{tabular}{lll}
\hline IASC standard sector & $\begin{array}{l}\text { USD committed/ } \\
\text { contributed }(\$)\end{array}$ & $\begin{array}{l}\text { USD } \\
\text { pledged }(\$)\end{array}$ \\
\hline Agriculture & $59,468,870$ & 0 \\
$\begin{array}{c}\text { Coordination and sup- } \\
\text { port services }\end{array}$ & $38,072,320$ & 0 \\
$\begin{array}{l}\text { Economic recovery } \\
\text { and infrastructure }\end{array}$ & $8,281,999$ & 0 \\
$\begin{array}{l}\text { Education } \\
\text { Food }\end{array}$ & $19,940,425$ & 0 \\
Health & $109,712,137$ & 0 \\
Mine action & $164,841,354$ & 0 \\
$\begin{array}{l}\text { Multi-sector } \\
\text { Protection / human } \\
\text { rights / rule of law }\end{array}$ & $4,248,879$ & 0 \\
$\begin{array}{c}\text { Safety and security of } \\
\text { staff and operations }\end{array}$ & $2,684,566$ & 0 \\
$\begin{array}{c}\text { Sector not yet } \\
\text { specified }\end{array}$ & $16,843,258$ & 0 \\
$\begin{array}{c}\text { Shelter and non-food } \\
\text { items }\end{array}$ & $56,446,889$ & 0 \\
$\begin{array}{l}\text { Water and sanitation } \\
\text { Total }\end{array}$ & $82,508,803$ & 0 \\
\hline
\end{tabular}

Source: Financial Tracking Service, generated 24 September 2012

Although it is recognized that education should be included in humanitarian responses, it continues to be under-financed. Although there are mechanisms to help increase funding of education in emergencies, ${ }^{29}$ education is still not prioritized, despite demonstrated efforts of its impact and role in mitigating conflict and contributing to peace-building. Whereas funding for humanitarian aid gives priority to life-saving assistance, it does not for medium- to long-term restoration of livelihoods, economic development, education, or psychosocial well-being. Martone writes, "The field of humanitarian assistance is compartmentalized in such a way that our attention is focused on immediate lifesaving measures and readily quantifiable indices like morbidity and mortality rates." 30 This distinction between humanitarian and development work is an old one, and this dualism implies that humanitarian and development work are inherently different, working toward different outcomes: humanitarianism toward immediate relief and development for more long-term and sustainable programming. ${ }^{31}$ But with many parts of Sudan in some sort of crisis, many that are chronic and exacerbated by poverty, 
how do affected populations describe the value of education in humanitarian work across the country?

\section{Methodology}

In order to explore whether or not education is an integrated component of the values and beliefs of Sudanese IDPs, we conducted education cluster-wide consultations as well as group and individual interviews. A total of 100 education officers were interviewed by the two authors in English or Arabic from 25 national and international civil society and non-profit organizations that provide education services in conflict-affected areas, as well as three United Nations agencies, and federal and state Ministries of General Education over the course of three months in the spring of 2012. Of those interviewed, 70 per cent were Sudanese, and all were working with and/or in conflict-affected states and populations in eight states: Blue Nile, Northern Darfur, Southern Darfur, Eastern Darfur, Khartoum, Northern Kordofan, Southern Kordofan, and White Nile. Each person was asked the same question: Donors are eager to provide humanitarian assistance, but with limited resources available, have concluded that water, food and health are sectors that have more importance in emergency situations in Sudan, than education. This has resulted in lower amounts of funding for education services than other service sectors. Having worked in camps and interacted with IDP and refugee communities, would you argue that IDPs and refugees share this perspective, or do they disagree? Why? Please support your responses with anecdotal evidence.

Because only secondary informants (i.e., field staff interacting with refugee and IDP community representatives) were interviewed, and only 100 informants were contacted, the qualitative data produced cannot be considered "representative" for all the opinions and considerations of Sudanese refugee and IDP community representatives. Nevertheless, the collection of anecdotal evidence from education cluster members working face-to-face with representatives of target populations across eight conflictaffected states was the most feasible and practical strategy to document perceptions across a vast country where communities and geographic areas are sometimes difficult, if not impossible, to access.

The arguments presented were then collected and clustered into eight recurring themes that emerged from the responses. The following section will discuss each of these themes.

\section{Findings: Importance of Education in Humanitarian Response \\ Education to Get a Job}

From the responses, education was framed as a way to break the poverty cycle by enabling individuals to attain jobs. One informant said, "Education is for people affected by emergencies: the only hope to rebuild and to break out of the cycle of poverty. People think that once their child is educated, it can get at least a low-paying job. They know that children who can write always have better chances to earn a job than those who do not, and they will be given priority." Education affords children an edge over others who are not necessarily as educated or educated at all. This advantage would lead them to some sort of paying position, which this informant claims is better than no job at all. Others viewed education as a way to leave Sudan for employment. One stated, "Even if you could not get a job inside Sudan, if you are educated you have a better chance for jobs if you manage to get outside of Sudan." And another participant said, "People know that many Sudanese have found employment as teachers in Gulf countries, and that by getting education they perhaps could follow in their footsteps." The bottom line is that opportunities available to the illiterate or uneducated are not the same. Access to relevant education also contributes to an increased "hope for a better future."

\section{Displacement Facilitates Access to Education}

Many respondents reported that IDPs would prefer to remain in camps where conditions may not be optimal, if there is access to education. "Availability of education services is one of the main reasons that people do not want to leave IDP camps," said one education officer. Another explained, "Wherever IDP camps provide education services, the enrolment rate is higher than the average (especially for girls who are not allowed to become breadwinners finding jobs in the market). IDP camps are no fun to live in, but people stay because of schools as well as other social services. If schools would close, some people would probably leave. Where there is access, children go to school and parents send their children to school. Grandparents comment, when looking at the facilities available in camps, that they wish they had the same opportunities [for education] when they were young."

IDP camp education, then, is framed as better than no education at all, and the elderly view it as a privilege that they did not have when they were younger. It is interesting to note how having a school in an IDP camp actually increases enrolment, with rates being higher than the average rate across the country, and with girls attending at higher rates. However, this does not mean that the education being received is of quality. Another education officer reported, "When villages outside of IDP camps are lucky enough to find NGOs who would build classrooms and provide education supplies in their localities, they usually attract returnees who are willing to resettle as long as the new locality has education opportunities for their children. People are 
unhappy in IDP camps due to lack of food aid, unemployment, and overcrowded schools. Education opportunities elsewhere could become a magnet to get people out of the camps.”

This participant shares the expectation of NGOs building new classrooms and quality education and does not necessarily mention the role of the government. Furthermore, the participant describes the poor conditions of the camps, including the overcrowded schools, and explains that perhaps a way to get people to resettle and move out of the camps is to provide education services that serve as a "magnet." For Sudanese families, then, where one lives could be a function of the education they have access to. For example, one participant said that of those South Sudanese who preferred to stay in Sudan after the referendum, their main motivation was that they expected their children to get better educated in the North. Another education officer said, "IDPs from conflict-affected areas in South Kordofan send their children to live with relatives in North Kordofan and Khartoum so that they can go to school there."

\section{Spend Limited Resources on Education}

Although technically basic education is free in Sudan, there are many related costs such as uniforms, textbooks, and fees to maintain the school building, among other things. A few participants observed that families valued education so much that they would indeed pay out of their limited finances to support their children's education. One asserted, "They support construction, fence construction, digging, foundation work, watering of trees, examination fees. Government pays only for teacher salaries and incentives. Sudan's education system may face serious challenges, but without the sacrifices of the people it would be in an even worse state."

It is clear that Sudanese are proud to be able to support education in any way they can, even if it puts additional burden on an already stretched financial situation. In $\mathrm{Al}$ Fashir, the capital city of North Darfur, IDPs were paying the transportation fees for their children to attend the secondary school located in the city because there was only a primary school in the camp. Also, in rebel-held areas of Jabel Marra in North Darfur, teachers are not paid and purely volunteer their services. Because they do not have money to pay the teachers, parents work in the teachers' farms as a form of payment. In the same area, students attend a school with no roof and sit on rocks. "But each rock carries the name of the student. This is an indicator of commitment and management." Despite having few resources, school and education continues to take place in Jabel Marra and in other conflict-affected areas across Sudan. Hence, in addition to being valued as a stepping stone for the future, education presents a shared value, and as such facilitates community action without external intervention.

\section{Education and Social Status}

Those who have education are leaders and in positions of power. One officer maintained, "Education and community leadership go hand in hand. Communities tend to elect those members who have the highest education. And it is a historic fact that the community leaders in particular strive to give their sons the best education possible in order to protect their influential roles in the community ... Parents want their children educated so that they have a chance of influencing community politics in the future."

There was also recognition that being educated affords advantage, even if one belongs to an ethnic group that is not a power holder in the political landscape of Sudan. One participant stated,

When in the 1990s many Sudanese emigrated to neighbouring Gulf states to benefit from the economic upswing as a result of increase in oil revenues, the government [of Sudan] needed to fill many vacancies within its own political administration. Because it could not find people of capacity within their own ethnic Jaaliyin and the Shayqiya networks, but also because it wanted to appear as inclusive and open, it recruited people of capacity from other ethnic groups, including southern states where citizens' features and colour of skin is certainly less Arab than in the North. This was certainly noted by members of the less-privileged or lessinfluential ethnic groups, because they recognized that education is an asset that opens doors into attractive positions of governments controlled even by rival ethnic groups.

And another said, "The Sudanese government seeks to support political alliances among influential stakeholders of different ethnic groups in order to sustain its influence and control of political affairs. If possible, the government would prefer to work with influential stakeholders who are also educated and skilled, as such alliances would make governance more effective. If one looks at high-ranking officials in government, parliament, or administration, one easily recognizes that the representatives from other ethnic groups are often local power-holders with an educational advantage over their ethnic brothers and sisters."

So even members of an ethnic minority can still be afforded a position of power or an added advantage in their own ethnic group and at the same time interact with the majority and the power-holders because they are educated. So even in a marginalized situation, the educated are afforded an advantage. This sentiment was not only shared about displaced people in Sudan but also presented as an example of exiled Eritreans found in Sudanese refugee 
camps. One participant asserted, "Although we are unable to provide sources or statistics, Eritrean refugees believe they have higher chances to be accepted in North America, Europe, or Australia when they have acquired some education and skills, than if they are uneducated." There is a general belief that education affords upward social mobility in Sudan or a way to leave the country altogether.

\section{Education Aids Integration}

Education can also level the playing field. "Nothing is common space. Not mosques, not neighbourhoods. But schools are common spaces for communities. Nobody says, 'This is our group's school.' A person might own a mosque, but one person does not own a school. People [have an opportunity to] talk if both their children attend the same school." School is seen as a place where everyone is equal and allows for a meeting ground of common expectations, to become educated. According to another respondent, "Schools facilitate co-existence. Schools where children attend are often the platform for representatives of different groups to come together and discuss their future as a people." In Muglad in Kordofan, an education officer said, "Schools are an opportunity for estranged communities to stay in touch and to prevent separatist tendencies." In bringing different populations together to obtain access for their children's education, schools integrate communities and directly contribute to peace-building. In Darfur, one participant noted, "People exchange bullets, but when it comes to education, they actually can agree." Remarkably, education facilitated collaboration even between the state Ministry of Education of South Darfur and rebel-held communities in Jabel Marra in 2010, when parents agreed to send their children to the capital city of Nyala to take their year-end exams, and the government authorities guaranteed their safe return. ${ }^{32}$ Education, then, is seen as an area of agreement and peaceful cohabitation, free of friction and conflict, and a means to prevent further deterioration of group and community relationships.

Additionally one participant pointed out, "After education, opportunities to join the army become an adolescent's second preferred option," meaning that the army is for those who do not have education as an alternative. One education officer who worked closely with former child combatants noted, "Ex-combatants reflect back on their lives; they regret their spoiled time in the military, and as they have grown old and have no way to access education again. And they say, 'Let's all fight for our children to get an education, as this world without education is useless. We cannot do anything, and we only speak a little Arabic. We cannot even write a letter or read. But if we had gone to school before, all could be fine for us. Life is hard without school."' Reflecting back on their lives, these former soldiers regret not being educated and hope that other children do not make the same mistake they made, enlisting in the army or participating (whether voluntarily or involuntarily is unclear) in combat as children or youth. Education is relevant to peacebuilding because soldiers prefer to access education rather than take up the career of a soldier.

\section{School Is Safe}

Schools are also safe spaces where children affected by conflict or disaster can re-experience a "sense of normalcy," or where they are protected from "negative influences" of children from the streets. One participant said, "When children do not go to school, they hang around with other out-ofschool children, and here the older children tend to bully and abuse younger children. They force them to join or contribute to gangs; they may become pocket thieves, start sniffing glue, and could become victims of sexual abuse."

When children are not in school, they are exposed to negative influences, but, as another participant reported, school is "a child-friendly space that makes children more cognizant because of their exposure to information and social interaction. These children speak better, distinguish [right from wrong] better, analyze better, ask better questions, and negotiate better." Children and youth who are in schools are safeguarded-at least temporarily-from the negative influences of being displaced, such as stress and violence, neglect, beating, and uncertainty. As one participant summed it up, "In a chaotic environment, schools are zones of safety, and the only zones that provide chances for development. Parents want their children to be in places where they are safe, and if they learn at the same time, that is an added advantage. If they do not participate in school, they will participate elsewhere, and that might not be to the best advantage of the child or family."

Interestingly, here school is seen both as a tool to learn coping skills such as distinguishing right from wrong and becoming a critical thinker, and also simply a safe space to be shielded from the negatives that come with being displaced. In this last quote, the participant shared that if children learned something it is a bonus. But even more important is the fact that that schooling keeps children and youth out of harm's way.

\section{Education Affords Knowledge, Honour, and Social Prestige}

For Muslims, education is a key to knowledge, and knowledge as the light of the mind. In addition, literacy and numeracy are also recognized as skills without which it is impossible to trade and communicate successfully across Sudan. The spread of Quranic schools and mosques across 
Sudan can be seen as a direct response to the religious and economic demand for basic education. ${ }^{33}$

Not surprisingly, IDPs and refugees view education as closely related to social prestige and honour, as well as a point of pride. Education brings "social benefits such as prestige and admiration in the community," shared one participant, and another said, "A drop-out child is not something to be proud of."

Beyond the social prestige and honour of being educated, education also serves as a way to avoid being duped or embarrassed. One respondent told us this story: "I was selling a chicken to an educated person for 5 piasters. The educated person then used the feathers of this chicken to make a pillow, which she then sold me for 10 piasters. It is education that enables the person to draw advantages from doing business with me."

Another participant shared this story: "A lady explained her appreciation for education after having received a letter that contained family secrets but that she could not read because she was illiterate. She showed the letter to somebody who could read but who loved to gossip, and soon the family secret was known to the whole community." In this example, education did not directly lead to an outcome such as a job or a position of power, but rather a sense of dignity. This woman was obviously embarrassed that because she could not read the letter, her secret was spread to the whole community.

Nomads whose migration patterns have become interrupted by conflict often are suspicious of formal education because it alienates their children from the nomadic way of life. At the same time, they acknowledge that "educated" veterinarians are able to save their cattle where traditional skills are insufficient. Trained midwifes have means to save lives that are unavailable among untrained Nomadic midwives. Leaders realize that nomads must learn to better relate to and interact with the non-nomadic world, but their way of life must be protected from influences of community life while accessing desirable social services.

\section{Education Is the Only Way to Become Less Dependent}

There was recognition that aid brought with it dependency, and that the form of aid that could help Sudanese IDPs gain independence from external support was investment in their education. "Food, water, and handouts create dependency, but education does not," said one participant. Another shared, "Handouts also create difficult attitudes, as Sudanese want to be paid and expect subsidies all the time. It spoils partnership development. Handouts kill the development [long-term] thinking of people." Another respondent relayed an elderly woman saying, "Don't just bring us sorghum. We can plant sorghum ourselves. Please help us to plant education." Another woman from Kordofan said,

We are very sorry for this situation, but mostly we, the elderly people, have no problems, but our main problem is not this food many are talking about. Our main problem is our children's education. When peace returns we can cultivate, and good food will be available. We use rainwater that our animals drink, and we can also survive in terms of water, but the biggest question is who will cultivate education for our children. We really cry for our children to get education in whatever condition it might be, even if under trees on rocks. They have to, for their future not to turn dark. This will help them stop thinking of the past conflict, and their psychology will be upheld. Educate our children, and after that you can provide us with what is available, but prioritize their education first.

Although here education is being requested from the aid and development agencies, it is being asked for so that ultimately their dependency upon aid can be reduced. As one participant said, "Our children's minds are fertile like the Abyei soil. Cultivate education." Education is a seed that needs to be planted now, to ensure that the children and youth of Sudan can grow independent of aid and development money.

\section{Discussion}

Prosperity, safety, protection, dignity, respect, influence, and status were all cited as reasons for how and why education is important, and why education should be a priority in humanitarian response. In some instances, education was valued even more than water, food, and health, but overwhelmingly education was seen as integral and necessary part of service delivery. Education mobilizes community action in places beyond the reach of government and aid agencies.

This evidence notwithstanding, critics might rightly argue that many families choose not to send their children to school. The high number of out-of-school children in Sudan is not just a consequence of limited donor funding for education programs. Some parents prefer that their children make money in the markets or help with household chores, contributing to family livelihood. Other parents are dissatisfied with the low quality and irrelevant education their children receive at school. For others, school is too far away, and they fear for the safety of their daughters. ${ }^{34}$

However, our evidence from Sudan shows that education is valued, and even when families are strapped for money, they are still willing to contribute to their children's education, because they consider it an important component of survival. If they refrain from investing in the education of 
their offspring, it is mostly in response to economic or social pressures, and not because they share the opinion of some humanitarian strategists that education is less important than water, food, or health services. Education was deemed a prerequisite for breaking the poverty trap by accessing jobs or leaving Sudan. Others viewed education as a way to gain social mobility and to be seen as more valuable in their community. Education was also perceived as safeguarding children from physical harm and levelling the playing field because it is a value shared by all.

While these thoughts are not necessarily surprising or new, they are rarely documented to inform future programs and, more importantly, funding priorities. With more attention being given to conflict-sensitive education, policymakers and donors need to note what those people, who daily live and deal with conflict, are saying. Education is important and plays a critical role in post-conflict development and the future of Sudan.

Although it is clear that education is underfunded and that an increase in education financing is needed, it is also important to move beyond this argument to critically examine the quality, adequacy, and relevance of education services for children and youth living in areas affected by chronic conflict or disaster. The type of education that needs to be provided must prepare the next generation to take ownership of the reconstruction of their communities and nations, rather than "alienating the disadvantaged even further from their own roots and from their potential for self-created social and economic advancement."35

\section{Conclusion}

No empirical evidence supports the argument that education leads to a more dignified survival in emergencies. But the narratives collected in this article indicate multiple rationales for why citizens in Sudan (and perhaps elsewhere) who are affected by conflict still view education as an essential component of human dignity that should be honoured by humanitarian and development aid. Education officers, who value education, collected the narratives of how and why education is valuable to IDP and refugee Sudanese populations. The purpose of this article was to provide a window into the lives of children and youth in Sudan through the anecdotes of those who work closely with them in the most conflict-affected regions across the country.

\section{Notes}

1. Disclaimer: The positions and conclusions presented in this article are those of the authors and do not reflect viewpoints of the organizations they have worked for, or where they are employed.
2. The Sphere Project, Humanitarian Charter and Minimum Standards in Humanitarian Response (Burton on Dunsmore: Schumacher Centre for Practical Action and Technology, 2011), 20; emphasis added.

3. Ibid., 22.

4. Ibid.

5. Gerald Martone, "Life with Dignity: What Is the Minimum Standard?", in Human Rights and Refugees, Internally Displaced Persons and Migrant Workers, ed. A. F. Bayesky, J. Fitzpatrick, and A. C. Helton, 129-44 (Leiden: Martinus Nijhoff Publishers, 2006).

6. Gerald Martone, "An Unexpected Lifeline," in Even in Chaos: Education in Times of Emergency, ed. K. M. Cahill, 89-108 (New York City: Fordham University Press, 2010).

7. These three areas are in strategic geographical locations between North and South Sudan and suffered the most from the ongoing war. As a result, in the Comprehensive Peace Agreement (CPA) of 2005, each of these areas was given its own protocols.

8. Joost van der Zwan, Evaluating the EU's Role and Challenges in Sudan and South Sudan: Sudan and South Sudan Case Study (London: International Alert, Initiative for Peacebuilding Early Warning, 2011), 11, http://www.ifp-ew.eu/ pdf/092011IfPEWSudan.pdf.

9. Ibid., 12.

10. United Nations Office for the Coordination of Humanitarian Affairs, Sudan Common Humanitarian Fund Annual Report 2011, https://docs.unocha.org/sites/dms/ Documents/Sudan\%20CHF\%202011.pdf.

11. Ibid.

12. World Bank, The Status of the Education Sector in Sudan (Washington: World Bank, 2012).

13. Ibid.

14. United Nations Office for the Coordination of Humanitarian Affairs, Weekly Humanitarian Bulletin Sudan, 20-6 August 2012.

15. Internal Displacement Monitoring Center, "Learning in Displacement," briefing paper on the right to education of internally displaced people (Geneva: Internal Displacement Monitoring Center, 2010); and World Bank, The Status of the Education Sector in Sudan (Washington: World Bank, 2012).

16. Ibid.

17. Elizabeth Ferris and Rebecca Winthrop, "Education and Displacement: Assessing Conditions for Refugees and Internally Displaced Persons Affected by Conflict," background paper for the Global Monitoring Report (Washington. DC: UNESCO, 2010), 7, http://www.refworld.org/ pdfid/4d7085712.pdf.

18. Ibid., 13. Countries include Sudan, Colombia, Iraq, Democratic Republic of Congo, Somalia, Pakistan, Turkey, Zimbabwe, Azerbaijan, and India.

19. Government of Sudan, Ministry of Social Welfare and Social Security, Sudan Millennium Development Goals 
Progress Report 2010, http://www.undg.org/docs/12273/ Sudan-MDG-Report-2010.pdf.

20. Government of Sudan (2008) Educational Statistics have listed 125,549 basic education students enrolled. If we assume that of the 2.62 million citizens are nomads, and 22 per cent children at the age where they should attend basic education (i.e., 576,400), then 78 per cent are not enrolled in basic education schools.

21. World Bank, The Status of the Education Sector in Sudan (Washington: World Bank, 2012), 8.

22. World Bank, "Investing in Your Country's Children and Youth Today: Good Policy, Smart Economics," Children \& Youth 4, no. 1 (August 2010): 1-4, http://www-wds.worldbank.org/external/default/WDSContentServer/WDSP/IB/ 2013/08/26/000356161_20130826164345/Rendered/PDF/ 806420NEWS0Inv00Box379809B00PUBLIC0.pdf.

23. World Bank, Status of the Education Sector in Sudan, 163.

24. The Cotonou Agreement is a treaty between the European Union and the African, Caribbean, and Pacific Group of States (ACP countries) and operates on four principles: equality of partnerships and ownership of development strategies; representative participation from all stakeholders, including the government and civil society; dialogue and mutual obligations that move beyond receiving money to include the upholding of human rights; and the agreements are differentiated and based on each country's unique situation. See van der Zwan, Evaluating the EU's Role.

25. Education is one of 11 clusters designated by the InterAgency Standing Committee (IASC) with the goal of strengthening humanitarian responses in emergencies. The other clusters are camp coordination and camp management; early recovery; emergency shelter; emergency telecommunications; food security; health; logistics; nutrition; protection; water, sanitation, and hygiene. For more information, see "What Is the Cluster Approach?" Humanitarian Response, https://clusters.humanitarianresponse.info/ about-clusters/what-is-the-cluster-approach.

26. J. Sparkes, E. van Kalmthout, and E. Martinez, "Education Cannot Wait: Humanitarian Funding Is Failing Children," Humanitarian Response, http://education.humanitarianresponse.info/system/files/documents/files/Education $\% 20$ Cannot\%20Wait\%20-\%20humanitarian\%20funding\%20 is\%20failing\%20children_1.pdf

27. The Sphere Project was launched in 1997 by a group of humanitarian NGOs, the Red Cross, and Red Crescent movements. It has produced the Humanitarian Charter and Minimum Standards in Disaster Response handbook, with the newest edition released in early 2011. For more information, see http://www.sphereproject.org/.

28. See "General Assembly Adopts Landmark Resolution Calling on States to Ensure Right to Education for Affected Populations in All Phases of Emergency Situations," news release, 9 July 2010, http://www.un.org/News/Press/ docs//2010/ga10964.doc.htm.
29. See Peter Buckland, "Alphabet Soup: Making Sense of the Emerging Global Architecture of Aid to Education in Fragile and Conflict Affected Settings," in Educating Children in Conflict Zones: Research, Policy, and Practice for Systemic Change, ed. Karen Mundy and Sarah Dryden-Peterson, 155-68 (New York: Teachers College, 2011). And see Janice Dolan, "Making It Happen: Financing Education in Countries Affected by Conflict and Emergencies," Save the Children, n.d., http://www.savethechildren.org.uk/sites/ default/files/docs/Making_it_happen.pdf.

30. Gerald Martone. "An Unexpected Lifeline," in Even in Chaos: Education in Times of Emergency, ed. K. M. Cahill (New York: Fordham University Press, 2010), 94.

31. Hugo Slim, "Dissolving the Difference between Humanitarianism and Development: The Mixing of a Rights Based Solution," Development in Practice 10, nos. 3-4 (2000): 21-5.

32. "Second-Chance' Examination for Schoolchildren Affected by Conflict in South Darfur," UNICEF Sudan, 14 July 2010, http://www.unicef.org/infobycountry/sudan_54297.html.

33. Neil McHugh, Holymen of the Blue Nile: The Making of an Arab-Islamic Community in the Nilotic Sudan 1500-1850 (Evanston: Northwestern University Press, 1994).

34. Government of Sudan, Federal Ministry of General Education, Baseline Survey on Basic Education in the Northern States of Sudan: Final Report 2008, 2008, http://doc.iiep. unesco.org/wwwisis/repdoc/E029336e.pdf.

35. Milton. J. Bennett, “Towards Ethnorelativism: A Developmental Model of Intercultural Sensitivity," in Education for the Intercultural Experience, ed. R. Michael Paige (Yarmouth: Intercultural, 1993), 42.

Friedrich W. Affolter is a graduate of the Center for International Education of the University of Massachusetts at Amherst. He served as the UNICEF education cluster coordinator in Sudan from 2010 to 2012. The author may be contacted atfaffolter@unicef.org.

Carine Allaf has worked with UNICEF, Save the Children, the Intra-Agency Network for Education in Emergencies (INEE), and Qatar Foundation International on education programs in Jordan, Palestine, Iraq, Sudan, Lebanon, and the United States. The author may be contacted at allaf@ exchange.tc.columbia.edu. 